\title{
La burguesía malagueña y sus promociones arquitectónicas de carácter religioso y asistencial (I)
}

\author{
Eva Maria Ramos Frendo
}

\begin{abstract}
E1 presente trabajo pretende mostrar algunas actuaciones de promoción arquitectónica de miembros de la burguesía decimonónica malagueña en las que les movieron principalmente razones de indole religiosa.

Incluimos también aquellas que tuvieron unos fines benéficos, por estar todas ellas impregnadas, a su vez, de esa religiosidad y servicio a los más necesitados que propaga el catolicismo.
\end{abstract}

This article studies some actions of architectonic promotion by members of the burgeoisie from nineteentn century in Málaga, motivated for religious reasons. We also include constructions of service to the poorest, actions promoted by the catholic religions.

La ciudad de Málaga, como numerosos estudios han ratificado ${ }^{1}$, vivirá un momento de gran esplendor en el segundo tercio del siglo XIX. Es en dicho periodo cuando se produce la reactivación de su comercio y el despegue industrial de la localidad. Unido a estos factores e impulsando los mismos estará un reducido grupo social ${ }^{2}$, una alta burguesía compuesta de una casi absoluta mayoría de inmigrantes, llegados tanto del extranjero como del interior de nuestra nación.

Esta serie de familias constituirán un coto muy cerrado, donde los matrimonios entre familiares o miembros del mismo clan evitarán que el control de los negocios y los patrimonios se dispersen ${ }^{3}$. El resultado será la formación de un grupo de élite, como también acontecerá en otras zonas de Andalucia ${ }^{4}$, que controlará todos los asuntos locales: políticos, económicos, sociales, religiosos y culturales. En el caso concreto de nuestra ciudad, este grupo de potentados será conocido con el nombre de oligarquía de la Alameda 5 .

Los miembros de esta oligarquía, al ser los que poseían el capital, tuvieron en sus manos, entre otras muchas cosas, el contribuir económicamente en la continuación o restauración de obras arquitectónicas o convertirse en los promotores de nuevas construcciones necesarias para su provincia.

RAMOS FRENDO, Eva María: “La burguesía malagueña y sus promociones arquitectónicas de caráctér religioso y asistencial $(\mathrm{I})^{\prime \prime}$, en Boletín de Arte $\mathrm{n}^{\circ} 24$, Universidad de Málaga, 2003, págs. 233-250. 
Si tras las empresas y sociedades de la época se repiten generalmente los mismos apellidos (Heredia, Larios, Orueta, Crooke, Parladé, Piédrola, Grund, Sánchez de Quirós, Roose, Sandoval, Schotlz, etc.), lo mismo sucede cuando nos acercamos a los financiadores de las edificaciones.

Diferentes fueron los motivos que llevaron a estos burgueses a costear nuevas obras o continuar las ya existentes: realizar obras benéficas y asistenciales ${ }^{\dagger}$; dotar a la provincia de los medios necesarios para la propagación de la fe católica; apoyar la educación, tanto de los más pobres como de sus propios miembros ${ }^{7}$; dotar a Málaga de un patrimonio decente; modernizar el aspecto de la ciudad; rentabilizar sus espacios por medio de construcciones destinadas a la especulación ${ }^{8}$; proporcionar a las clases obreras viviendas dignas o buscar con dichos actos la consolidación de su prestigio.

\footnotetext{
${ }^{1}$ Entre ellos GÁMEZ AMIÁN, A.: Fermín Alarcón Luján: un empresario capitalista en la Málaga de la segunda mitad del siglo XIX. Málaga, Diputación, 1990; JIMÉNEZ QUINTERO, J.A.: "Industria Malagueña, S.A.", Jábega nº 15, Málaga, Diputación, 1976, págs. 58-65; LACOMBA, J. A.: Sociedad y política en la primera mitad del siglo XIX. Málaga, Ágora, 1989; Idem: Crecimiento y crisis de la economía malaguefía, Málaga. Diputación, 1987 y MORALES MUÑOZ, M.: Economía y sociedad en la Málaga del siglo XIX, Málaga. Diputación, 1983.

${ }^{2}$ Reducido en cuanto número por ser un porcentaje mínimo de la totalidad de la población de la ciudad, pero poderosos en cuanto ámbito de influencias.

${ }^{3}$ Sobre quiénes fueron estas familias y los enlaces realizados entre ellos RAMOS FRENDO, E. M.: El Coleccionismo en la Málaga Decimonónica. Málaga, Universidad, Tesis Doctoral inédita, 2002, especialmente las páginas 66-71.

"MORALES MUÑOZ, M.: "El papel de las elites en la industrialización andaluza", Baetica. Estudios de Arte, Geografía e Historia n ${ }^{\circ}$ 21, Málaga, Universidad, 1999, págs. 431-449. ${ }^{5}$ Nombre surgido de la boca del escritor costumbrista Serafín Estebánez Calderón y usado de manera despectiva para nombrar al grupo formado por su suegro Tomás Livermore Page y sus cuñados Manuel Agustín Heredia, Miguel Bryan, Martín Heredia, José de la Cámara y José Salamanca. En la actualidad ha perdido su carácter peyorativo y se utiliza para referirnos a ese conjunto de familias de constituyeron esa alta burguesía dirigente de la Málaga del siglo XIX.

${ }^{6}$ Todas estas acciones se encuentran recogidas en la obra de MATEO AVILES, E. de: Paternalismo burgués y beneficencia religiosa en la Málaga de la segunda mitad del siglo XIX, Málaga, Diputación, 1985.

${ }^{7}$ Dentro de estas intervenciones destacará la Marquesa de Casa Loring, Amalia Heredia Livermore y su papel para instaurar en nuestra ciudad el colegio de la Asunción destinado a la eđucación de las jóvenes de la alta burguesía local. RAMOS FRENDO, E. M.: "El colegio de La Asunción de Málaga y Amalia Heredia Livermore: Historia de dos vidas paralelas", Boletín de Arte $\mathrm{n}^{\circ}$ 20, Málaga, Universidad, 1999, págs. 191-210.

${ }^{8}$ Este fin es perseguido en muchas de las construcciones financiadas por don Manuel Agustín Heredia, como podemos observar en el estudio realizado en ORDÓÑEZ VERGARA, J.: Ciudad y gestión privada (M. A. Heredia. Málaga. $1^{2}$ mitad del siglo XIX), Málaga, Universidad, 1991, especialmente en las páginas 103-135, pero también se podrá apreciar en otros muchos burgueses de la época como don Antonio María Álvarez o don Antonio Campos. Para estos últimos consultar ORDÓÑEZ VERGARA, J.: "La ciudad burguesa y comercial" y MORALES FOLGUERA, J. M.: "La ciudad aristocrática" en SAURET GUERRERO, T. (Coor.): De la ciudad aristocrática a la burguesa: el centro histórico de Málaga. Málaga, Universidad, 1993, págs. 38 41 y 106-108 respectivamente.
} 
Guiados por una o más de estas razones, estos burgueses van a estar tras toda obra de gran envergadura que se realice durante dicho periodo.

En este caso concreto nos vamos a acercar a algunas construcciones cuyos principales móviles, aunque no por ello los únicos, fueron de tipo religioso, entendiendo por religiosos aquellos que tuvieron como fin permitir la difusión de la religión cristiana, es decir las parroquias o capillas, o poner en práctica la caridad, algo a lo que tradicionalmente estaba obligada toda persona católica adinerada para de este modo paliar, en alguna medida, las carencias de los más necesitados.

A pesar de que hablamos de móviles religiosos, estos no serían los únicos, dado que tras cualquier obra promovida por los miembros de esta alta burguesía, además de otras razones, se encontraría siempre el contribuir de cara al resto de la localidad a reforzar su prestigio. Al acercarnos a algunas edificaciones religiosas promovidas en los dos últimos tercios del síglo XIX nos encontramos, entre otros, con dos de los apellidos más sonados de la época: los Heredia y los Larios.

\section{LA FAMILIA HEREDIA:}

La familia Heredia ${ }^{9}$ y sobre todo algunos de sus miembros destacaron por su gran religiosidad y continuas actuaciones en favor de los más necesitados.

\section{TOMÁS HEREDIA LIVERMORE Y JULIA GRUND CERERO:}

Sobresaldría Tomás Heredia Livermore ${ }^{10}$ (FiG. 1) considerado el burgués más influyente en el plano religioso de la Málaga del siglo $X I X^{11}$ y responsable de numerosas donaciones destinadas tanto al culto y prosperidad de la iglesia como al auxilio de los pobres ${ }^{12}$.

\footnotetext{
${ }^{9}$ Entendemos por familia Heredia a los diversos descendientes del industrial don Manuel Agustín Heredia Martínez (sobre este personaje GARCÍA MONTORO, C.: Málaga en los comienzos de la Industrialización: Manuel Agustín Heredia (1786-1846), Universidad de Córdoba, Instituto de $\mathrm{H}^{\mathrm{a}}$ de Andalucía, 1978) y a aquellos otros que se unieron a la tnisma a través de los matrimonios.

${ }^{10}$ Cuarto hijo del matrimonio formado por don Manuel Agustín Heredia e Isabel Livermore Salas.

${ }^{11}$ MATEO AVILÉS, E. de: Piedades e impiedades de los malagueños en el siglo XIX, Málaga, eđita el autor, 1987, pág. 42.

${ }^{12}$ La Unión Mercantil, 4 de agosto de 1893.
} 
1. Tomás Heredia Livermore

Según palabras del canónigo don Miguel Bolea y Sintas, don Tomás fue uno de los más generosos bienhecho$r e s^{13}$ de la Catedral malagueña. Concretamente, para la Capilla de la Encarnación, en el año 1881, costeó las tres vidrieras de colores que representaban a los dos Santos Patronos Mártires San Ciriaco y Santa Paula en los laterales y el Misterio de la Encarnación en la vidriera central.

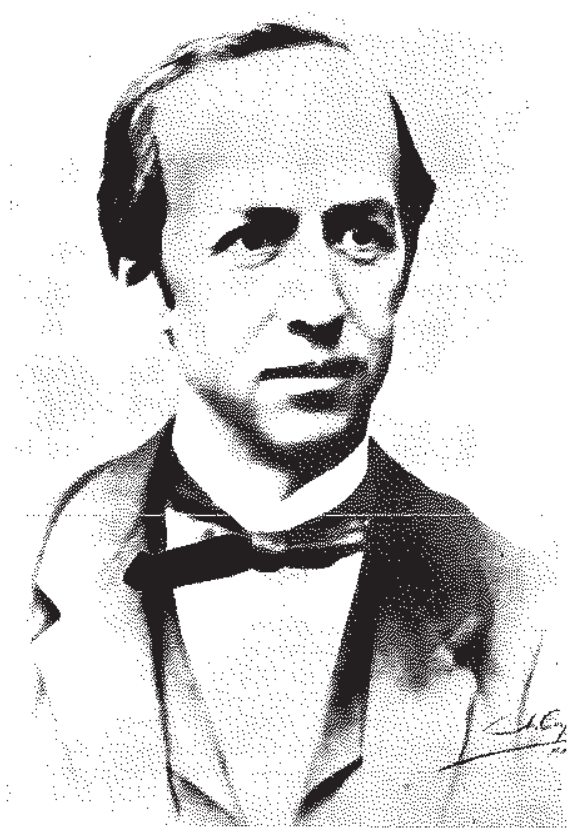

Tomás Heredia fue además el último Cónsul de los Estados Pontificios en la ciudad de Málaga y un asiduo benefactor del Cabildo Catedralicio al proporcionarles numerosos donativos en metálico a fin de contribuir a los costos de las diversas celebraciones acontecidas en nuestra Santa Iglesia Catedral.

Por ésta y otras muchas labores que habian contribuido al ornato y embellecimiento de la Santa Iglesia sería agasajado con el honor de poder ocupar el asiento número cuatro del coro de Arcipreste de dicha catedra! ${ }^{14}$.

Todos sus desvelos por la ciudad de Málaga, y de manera especial por todas las cuestiones religiosas y benéficas, harían que nada más acontecido su fallecimiento el Excelentísimo e Ilustrísimo señor don Marcelo Spínola y Maestre, obispo de la catedral malagueña, marchara con gran premura a visitar a la familia ${ }^{15}$. Esa misma acción fue la seguida por la gran mayoría de los malagueños, independientemente de la clase social a que pertenecieran.

${ }^{13}$ BOLEA Y SINTAS, M. (1894): Descripción Histórica que de la Catedral de Málaga hace su Canónigo Doctoral..., Málaga, Universidad, Edición Facsímil, 1998, pág. 257.

${ }^{14}$ Ibídem, pág. 317.

1̄ La Unión Mercantil, 4 de agosto de 1893. 
2. Julia, a la izquierda, y Trinidad Grund Cerero

El privilegio de contar con un asiento en el coro de la Catedral también recayó en su esposa Julia Grund Cerero $^{16}$ (FG. 2) por ser considerada una dama que habia destacado por su piedad y munificencia ${ }^{17}$ para con dicha iglesia. Según palabras de don Narciso Díaz de Escovar: Las iglesias, los conventos y los asilos lograron de doña Julia Grund valiosos y frecuentes donativos $^{18}$.

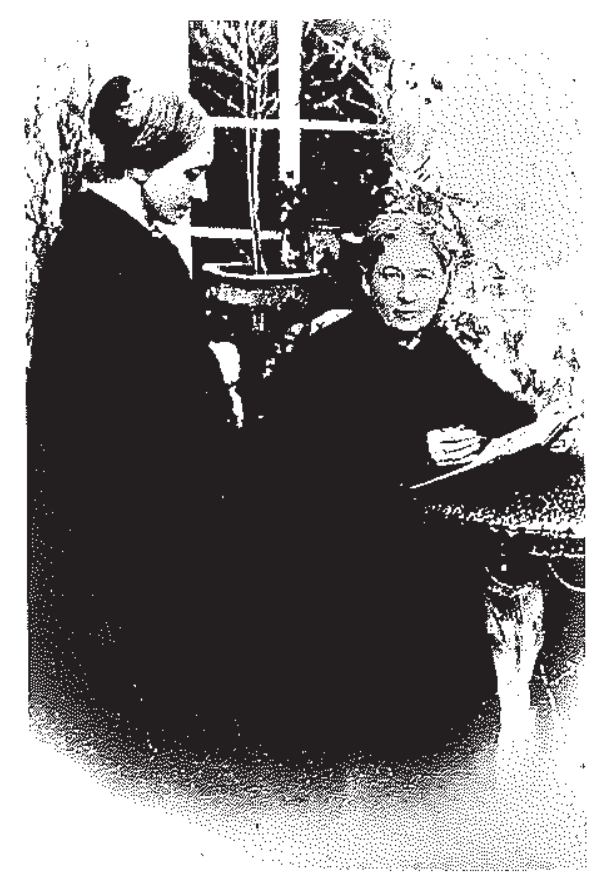

Y así nos lo demuestra la prensa de la época. Destacamos su intervención en la junta que se creó para obtener fondos con destino a la adquisición de las piezas necesarias para el culto (crucifijos, candeleros, lámparas, etc.) de la recién creada Parroquia de San Pablo de Málaga ${ }^{19}$. Con este fin tendría lugar la celebración de una rifa ${ }^{20}$, método muy empleado para otras muchas obras de carácter benéfico. Junto a doña Julia también se encontrarían en la citada junta doña Carlota Hernández de Cendra y doña Victoria Duarte de Heredia ${ }^{21}$.

Se creó una comisión encargada de la recogida de objetos destinados a la rifa de la que formaron parte los señores Moreno Castañeda, Bolín, Cámara, Rodríguez, Sandoval, Rein, Schotlz, Gaetner, Miró y Fresneda. Ya desde los primeros días se recibirian numerosas piezas, entre las que existían algunas de gran valor y mérito. Concretamente, la prensa destacaba, entre otros, un hermoso cuadro al óleo, anti-

${ }^{16}$ Hija de don Federico Grund, natural de Hamburgo, y doña Trinidad Cerero Arroyal de Sevilla. Casada con Tomás Heredia Livermore el 2 de enero de 1848.

${ }^{17}$ BOLEA Y SINTAS, M. (1894): Descripción Histórica... op. cit., pág. 316.

${ }^{18}$ (A)rchivo (D) ́raz de (E)scovar, Caja 168, no 12, Julia Grund de Heredia.

19 HERRERA SIERRRA, F. J.: "Fe e historia como anhelo del arte. La iglesia de San Pablo de Málaga", Boletín de Arte n $^{\circ} 21$, Málaga, Universidad, 2000, págs. 213-232.

${ }^{20}$ La Unión Mercantil, 23 de Mayo de 1891.

${ }^{21}$ Ibídem. 


\section{Amalia Heredia Livermore}

guo, de D. Tomás Heredia ${ }^{22}$. Además de objetos para la rifa, otros malagueños realizarían regalos bien de piezas necesarias para el culto y ornato de la iglesia o donaciones en metálico para ayudar a la compra de lo que fuera necesario ${ }^{23}$.

Este matrimonio, junto a otras familias de la burguesía malagueña, también participó activamente en la

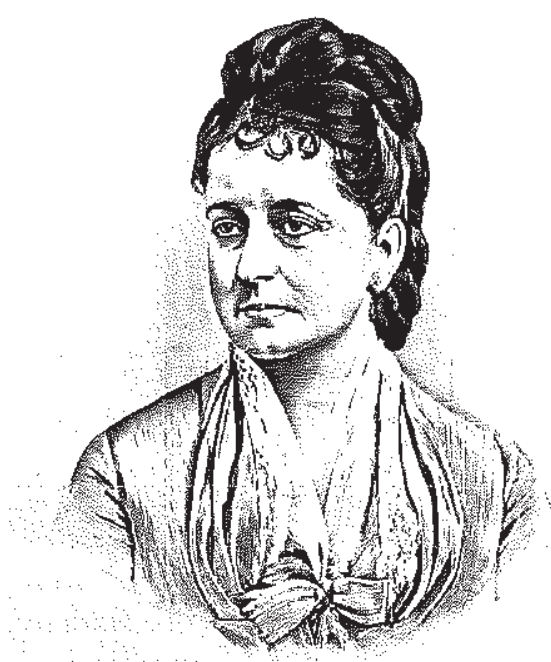

EXCMA GKA D. AMATIA HEREDIA DE LIWERMORE MARQUUESA DE OASA LORING. fon Mátige el din it del corrtonto.

$1 k$, stlatinfitit. reimplantación de órdenes religiosas, como la de los jesuitas, acontecida en $\uparrow 881$ y que hizo posible la creación del Colegio de San Estanislao del Palo ${ }^{24}$, gracias a la constitución de una Sociedad Constructora que por medio de acciones permitió iniciar las obras de dicho centro el 1 de octubre de 1881, el cual sería inaugurado el 2 de octubre de 1882. Se trata de una construcción proyectada por Jerónimo Cuervo González y dirigida por el hermano jesuita Hilarión Espalza que era arquitecto y el hermano Soriano, de profesión carpintero ${ }^{25}$.

Además, Tomás también ayudaría a su hermana Amalia Heredia Livermore ( $F$ G 3 ) en hacer realidad la creación de un colegio destinado a la educación de las jóvenes de la alta burguesía malagueña, el Colegio de La Asunción ${ }^{26}$.

Igualmente, con fines educativos y asistenciales, pero en este caso para los hijos de las obreras que trabajaban en las diversas industrias de la capital, Tomás Heredia

\footnotetext{
${ }^{22}$ La Unión Mercantil, 27 de mayo de 1891.

${ }^{23}$ La Unión Mercantil, 30 de mayo de 1891. Nos realiza una relación de muchas de estas donaciones con la especificación, en algunos casos, del nombre del donante.

${ }^{24}$ MATEO AVILÉS, E. de: Pieđades e impiedades... op. cit, págs, 44-45.

${ }^{25}$ RODRÍGUEZ MARÍN, F. J.: Málaga Conventual. Estudio Histórico, Artístico y Urbanístico de los Conventos Malaguefíos. Málaga, Arguval, CajaSur, 2000, págs. 312-313.

${ }^{26}$ RAMOS FRENDO, E. M.: "El colegio de La Asunción... op. cit.
} 
decide, en abril de 1859, construir en unos terrenos de su propiedad, ubicados en la calle de la Cruz del Molinillo, una escuela para evitar que los hijos de dichas obreras tuvieran que vagar abandonados durante la mayor parte del día, por no tener sus madres con quien ni donde dejarlos.

El diseño de esta futura escuela, la Escuela de Párvulos de San Juan de Dios, será ejecutado por don José Moreno Monroy y aprobado por el arquitecto municipal don José Trigueros ${ }^{27}$. Durante toda su vida Tomás Heredia como presidente de la institución asistencial denominada Conferencias de Caballeros de San Vicente de $P_{a u}{ }^{8}$ velará por el mantenimiento de este establecimiento en que tanto él como otros muchos miembros de la burguesía malagueña contribuyeron como socios activos.

Para concluir con este personaje y sus labores a favor de la religión católica resultan enormemente ilustradoras las palabras que con motivo de su fallecimiento, acontecido el día 3 de agosto de 1893 cuando contaba 74 años de edad ${ }^{29}$, se emitieron y que a continuación exponemos:

Nadie en Málaga ignora lo que valia el Sr. Heredia, siendo muy pocos los que no hayan recibido valiosos beneficios de su mano caritativa, sobre todo en los días prósperos en que sus negocios marchaban bien. Apenas habrá templo que no le deba en parte, o su conservación, o su embellecimiento, apenas existirá Comunidad religiosa, que no recuerde actos de generoso desprendimiento del insigne finado ${ }^{30}$.

\section{TRINIDAD GRUND CERERO, VIUDA DE. HEREDIA:}

Al igual que ocurriría a su hermana Julia, Trinidad, mayor de las hijas del matrimonio Grund, entronca con la familia Heredia a través de su matrimonio con don Manuel Heredia Livermore, celebrado igualmente el 2 de enero de 1848. La suerte de su hermana no será la suya, pues el que será su esposo sufrirá numerosos desequilibrios nerviosos que le llevarán finalmente a quitarse la vida en el año 1853, cuando ella esperaba el tercer hijo del matrimonio.

\footnotetext{
${ }^{27}$ BARRIOS ESCALANTE, C., FERNÁNDEZ BORREGO, A. y NUÑEZ GALIANO, P: "La Escuela de Párvulos de San Juan de Dios, proyecto de Moreno Monroy, actual colegio Goleta", Jábega n ${ }^{\circ}$ 61, Málaga, Diputación, 1988, págs. 42-51.

${ }^{28}$ MATEO AVILES, E. de: Paternalismo burgués... op. cit, págs. 92-97.

${ }^{29}$ La Unión Mercantil, 3 y 4 de agosto de 1893. El día tres la prensa nos anuncia del estado de gravedad en que se encuentra, produciéndose al día siguiente la noticia del fatal desenlace acontecido a las cinco y media de la madrugada.

${ }^{31}$ Boletín Español Oficial de la Provincia, 1893, pág. 676. Palabras recogidas en MATEO AVILÉS, E. de: Piedades e impiedades... op. cit., págs. $42-45$.
} 
Esta sería la primera de sus numerosas desgracias, pues poco después perdió a su único hijo varón y el 29 de marzo de 1856 perecerian sus dos hijas en el naufragio del vapor Miño, acontecido al chocar el mismo contra un buque inglés, cuando varios miembros de la familia Heredia se dirigían hacia la feria de Sevilla.

Estos acontecimientos serán cruciales para transformar la vida de esta mujer que, a partir de esos momentos, pasa a jugar un papel muy relevante dentro de las actividades de beneficencia acontecidas en la capital malagueña. Su desgracia la hizo volcarse y comprometerse con los más necesitados de la localidad, convirtiéndose, como en la época la denominaban, en la heroína de la caridad malagueña $a^{31}$ o también llamada por el escritor costumbrista Serafín Estébanez Calderón, la Virgen de la Victoria, porque decía que era el amparo de todos los malagueños ${ }^{32}$.

Su obra más notable sería sin duda el Asilo de San Manue ${ }^{\beta 3}$, institución de caridad por ella misma sufragada, fundada el 2 de julio de 1859 y destinada al cuidado, educación, alimentación y alojamiento de los niños más pobres por parte de la Hermanas de la Caridad de San Vicente de Pauß4.

La prensa de la época nos ha dejado constancia de todo el proceso de creación de este establecimiento, para cuya edificación doña Trinidad hizo venir desde Cádiz a un arquitecto ${ }^{35}$, que sería el encargado de concluir lo que durante algún tiempo había quedado interrumpido.

El edificio estaba situado entre las calles de San Andrés y La Constancia y ya incluso antes de su fundación, tenía en él alojadas hasta ciento y siete personas, viudas pobres, con hijos de menor edad, a las cuales da habitación y sustento sano, nutritivo y abundante ${ }^{36}$. Numerosas eran las palabras de elogio que recibía esta mujer descrita como ilustrada, virtuosa, caritativa, modesta y reservada.

Además de esta fundación, también participó en otras muchas actividades con fines caritativos. Como miembro de la Sociedad de Beneficencia Domiciliario de San Juan de Dios, Trinidad sería la encargada directa del reparto de pan y sopa a los pobres de nuestra ciudad ${ }^{37}$. Igualmente, ocuparia el cargo de presidenta de una Junta

\footnotetext{
${ }^{31}$ SUAREZ, F: Memorias del gobernador Antonio Guerola. Málaga 1857-63. Málaga en la segunda mitad đel siglo XIX. Málaga, 1995, Tomo 1, pág. 207.

${ }^{32}$ HEREDIA GRUND, M. P, Memorias de una nieta de Manuel Agustín Heredia. Madrid, 1955, pág. 18.

${ }_{33}$ MATEO AVILES, E. de: Paternalismo burgués...op. cit., págs. 62-63.

${ }^{34}$ El Avisador Malaguefro, 27-1-1860.

${ }^{35}$ Ibídem, 20-3-1858.

${ }^{36}$ Ibídem, 30-3-1858.

${ }^{37}$ MATEO AVILÉS, E. de: Paternalismo burgués... op. cit., pág. 98.
} 
de Señoras que se creó bajo la protección del gobierno, buscando en Málaga un grupo de damas que intervinieran en los distintos establecimientos benéficos de forma similar a como lo hacian las Damas Nobles de Madrid ${ }^{38}$.

Otro colectivo con el que se solidarizó y atendió, como nos indicaba la prensa de la época, con toda clase de auxilios y socorros, fue el de los náufragos, con los que ella, por su desgracia personal, se sentía muy identificada ${ }^{39}$.

Finalmente, para dar una ligera idea de la caridad que siempre guió a esta señora, destacamos que formó parte de un grupo de damas de la alta burguesía malagueña que se volcaron en ayudar a los heridos que llegaban a nuestra ciudad procedentes de la guerra de África. Para contribuir a mejorar los padecimientos de estos jóvenes, primeramente se dedicaron a hacer vendas con destino a los establecimientos hospitalarios, pero esto no les pareció suficiente y tal y como nos expone el gobernador don Antonio Guerola:

...no satisfechas las señoras de Málaga con lo mucho que hacian por los heridos, y con tener casi todas ellas alguno alojado en su casa, once de ellas se reunieron y acordaron establecer a su costa y con toda magnificencia un hospital para oficiales heridos ${ }^{40}$.

El lugar escogido para esta encomiable labor fue el Hospital de San Julián y las once damas citadas eran, además de Trinidad, su hermana Julia Grund, su cuñada Amalia Heredia Livermore, Rosario Oyarzábal de Loring, María Sánchez de Quirós de Parladé, Carmen Sánchez de Quirós de Freuller, Ana Sánchez de Quirós de Parladé, Maria Loring de Delius, Mercedes Sánchez de Quirós, Rafaela Roose de Sánchez de Quirós y María Heredia de Parladé.

Esta elogiada acción en bien de los heridos de la guerra de África fue concluida en junio de $1860^{41}$ cuando se decidió cerrar entre los días 10 y 11 de junio el citado hospital por no ser ya necesario.

Por ésta y las otras muchas labores que llevamos mencionando y otras que no hemos citado, doña Trinidad Grund fue agasajada con la banda de María Luisa ${ }^{42}$.

${ }^{38}$ SILVELA, F: $D^{a}$ Trinidad Grund de Heredia. Necrología, Málaga, Gilabert, 1896, pags. 14-15.

39 El Avisador Malagueño, 10-1-1860.

${ }^{40}$ SUÁREZ, F.: Memorias del... op. cit., pág. 39. SILVELA, F: Da Trinidad... op. cit., pág. 14. El Avisador Malagueño, 18-1-1860.

${ }^{41}$ El Avisador Malagueño, 10-6-1860.

${ }^{42}$ Ibidem, 18-1-1860. 


\section{ANDRÉS PARLADÉ SÁNCHEZ DE QUIRÓS, II CONDE DE AGUIAR Y MARÍA HEREDIA LIVERMORE:}

El dotar a nuestra provincia de las iglesias necesarias para que todos los fieles pudieran contar con un lugar donde recibir los distintos sacramentos fue labor también emprendida por otros miembros de esta misma familia.

Una de estas acciones la protagonizaron el matrimonio formado por don Andrés Parladé Sánchez de Quirós, II conde de Aguiar y doña María Heredia Livermore.

Andrés era hijo de don Pablo Parladé y Llucia ${ }^{43}$, natural de San Pedro de Rindevillas, en el Principado de Cataluña y de doña María de la Natividad Sánchez de Quirós, condesa de Aguiar, natural de Lima, en Perút ${ }^{44}$. Tanto la familia paterna como la materna destacaban entre los comerciantes capitalistas de Málaga, que tenían residencia en la Alameda.

María Heredia Livemore, por su parte, era hija de don Manuel Agustín Heredia e Isabel Livermore. Había nacido en Montpellier, Francia ${ }^{45}$. Fue una de las supervivientes, al igual que su tía Trinidad Grund, del naufragio del vapor Miño, acontecido, como ya exponíamos anteriormente, el día 29 de marzo de $1856^{46}$.

Andrés entroncaría con la familia Heredia al contraer matrimonio con Maria, la menor de los hijos del destacado ferretero, el día 15 de abril de $1857^{47}$.

Este matrimonio actuaría como únicos promotores de una construcción de carácter religioso, una iglesia o capilla para el partido rural de Arroyo de la Miel.

BREVE HISTORIA SOBRE EL ARROYO DE LA MIEL:

Arroyo de la Miel, territorio entregado por los Reyes Católicos al obispado malagueño, fue vendido por éste, hacia el siglo XVII, a la familia Zurita-Zambrana quienes establecen allí un cortijo. Dichos terrenos pasan a formar parte de un mayorazgo y vínculo fundado por el capitán y regidor don Fernando de Zurita, por el

\footnotetext{
${ }^{43}$ Don Pablo Parladé aparece en la Guía de 1861 como miembro de los comerciantes capitalistas de Málaga y entre los navieros de la misma. VILÁ, B. (1861): Guía del Viajero en Málaga. Málaga, Eđición Facsímil, 1998, págs. 393 y 395.

44 (A)rchivo (H)istórico (P)rovincial de (M)álaga, Escribanía de don Miguel Cano de la Casa, leg. 5045, 1858, Testamento de don Andrés de Parladé y Sánchez de Quirós, fols. 258-262.

45 A.M.M., Padrones, ${ }^{\circ} 158 / 1$, fol. 77.

46 El Avisador Malagueño: 1 de abril de 1856.

${ }^{47}$ A.H.P.M., Escribanía de don Miguel Cano de la Casa, leg. 5045, 1858, Testamento de dofía María Heredia y Livermore de Parladé, fols. 263-266.
} 
cual dicho cortijo, junto a otros bienes, permanecerian durante más de dos siglos en poder de esta familia, siendo heredados siempre por los hijos mayores de los distintos matrimonios ${ }^{4 \mathrm{~B}}$.

El 19 de noviembre de 1784 el cortijo, junto a una serie de hipotecas que el mismo poseía, seria comprado por el genovés Félix Solecio ${ }^{49}$ a don Pedro de Reyes, quien a su vez lo habia adquirido de la familia Zurita-Zambrana poco antes. Arroyo de la Miel pasa así a convertirse en una barriada, libre ya de las caracteristicas de feudo medieval, que irá poco a poco modernizándose.

La compra se debió a que por estas fechas Félix Solecio buscaba un lugar donde hubiera abundante agua, necesaria parar mover maquinaria hidráulica utilizada en la fabricación de papel blanco, destinado este último a la fabricación de barajas de cartas en la Real Fábrica de Naipes de Macharaviaya. En los terrenos de la familia Zurita-Zambrana encontraría el manantial del Arroyo de la Miel, denominado el Cao, que seria un lugar idóneo para la fundación de las fábricas.

Alli inicia la creación de diversas fábricas, un acueducto para canalizar las aguas del manantial, viviendas para los operarios, explotaciones agrícolas y toda otra serie de inversiones, entre las que se encontrará la construcción de una mansión en calle Granada, frente a la iglesia de Santiago ${ }^{50}$, que le irán cargando de deudas ante las que se verá incapaz de remontar. Tras la ruina de Félix Solecio y su familia, las fábricas de papel serian destruidas por sus propios operarios, pero tras estas desagradables circunstancias en el Arroyo de la Miel quedará constituida una población.

A mediados del siglo XIX, tanto Benalmádena como Arroyo de la Miel van a convertirse en terrenos codiciados por los inversores que desean adquirir espacios donde dedicarse al cultivo de la vid. En el Arroyo de la Miel también se explotarán

\footnotetext{
${ }^{48}$ BAQUERO LUQUE, J.: "Benalmádena en los siglos XVIL-XVIII", en AA.VV., Una Historia de Benalmádena. Benalmádena, Ayuntaniento, págs. 201-229. Agradezco a Belén Ruiz haberme puesto en contacto con esta obra.

${ }_{49}$ Felix Solecio llega a la capital malagueña en 1776 debido al interés mostrado por los hermanos Gálvez de Macharaviaya. Este genovés era especialista en la fabricación de papel que los Gálvez necesitan para la fabricación de las barajas de cartas de su Real Fábrica de Naipes. Sobre los Gálvez ver JIMÉNEZ QUINTERO, J.: "El Panteón de los Gálvez de Macharaviaya", Jábega n ${ }^{\circ}$ 7, Málaga, Diputación, 1974, págs. 45-48; MORALES FOLGUERA, J. M.: Los Gálvez de Macharaviaya. Málaga, Benedito, 1991 y SANTOS ARREBOLA, M. S.: La proyección de un ministro ilustrado en Málaga: José de Gálvez. Universidad y CajaSur, 1999.

${ }_{50}$ Se trata del conocido como Palacio del Marqués de la Sonora. Ver MORALES FOLGUERA, J. M.: La Málaga de los Borbones. Málaga, 1986, págs. 229-230.
} 
la batata y un total de seis minas de hierro. Por estas fechas la familia Ruiz Pastor fundará una colonia que atraerá a numerosos jóvenes que se afincan en este lugar ${ }^{51}$. Muchos de estos inmigrantes se casarán con muchachas de la localidad provocando un importante crecimiento de la población. El mayor auge tendrá lugar en el año 1850.

\section{LA CAPILLA DEL ARROYo de LA Miel:}

Por estas circunstancias, el matrimonio Parladé, al percatarse de que en esta zona, en unos pocos años, se habia multiplicado el número de vecinos y, como expresaba el matrimonio, carecian del pasto Espiritual, tan necesario y preciso para elevar nuestras almas al Divino Creador ${ }^{52}$, dado que la parroquia más cercana se encontraba en Benaimádena y distaba media legua de aquel lugar, se plantearon como solucionar el problema.

$\mathrm{Y}$, de este modo, con el fin de subsanar esa carencia, don Andrés Parladé y su esposa se propusieron edificar una iglesia en dicho partido. Por esta razón, don Andrés adquirió a don Fernando Rumbado Morales media fanega de tierra de regadío perteneciente a la hacienda de campo llamada de las Pedrizas, propiedad de éste último, que lindaba con tierras de don Juan Peralta, don Epifanio Iglesias Castañeda y doña Josefa Gutiérrez Quijano ${ }^{53}$. La venta quedó registrada en escritura realizada el 8 de mayo de $1861^{54}$.

Posteriormente, se realizó el proyecto para la construcción de la mencionada iglesia, que fue aprobado por Real Orden el 27 de junio de 1861. Dicha aceptación fue comunicada al entonces obispo de Málaga, don Juan Nepomuceno Cascallana y Ordoñez, quien dio al señor Andrés Parladé su consentimiento y beneplácito para que de conformidad con el plano aprobado, se íniciara la edificación de la citada capilla, una vez fuera bendecido el lugar.

\footnotetext{
${ }^{51}$ Algunos años después, don Jorge Loring Oyarzabal, también miembro de la familia Heredia por su matrimonio con Amalia Heredia Livermore, comprará diversos terrenos del antiguo Cortijo del Arroyo de la Miel, entre los que se encontrarán gran número de propiedades de esta familia. A.H.P.M., Escribanía de don Teodoro Díaz Quintana, leg. 5252, 1882, fol. 305 y ss. ${ }^{52}$ A.H.P.M., Escribanía de don Manuel Romero de la Bandera, leg. 4699, 1865, Donación de uso de una Iglesia, ornamentos y vasos sagrados por los señores don Andrés Parladé y doña María Heredia Livermore, fol. 266v.

${ }^{53}$ Señora viuda y residente en Pueblo de Somachos, Santander que poseía gran parte del antiguo cortijo de Arroyo de la Miel. A.H.PM., Escribanía de don Francisco López Bueno, leg. 4483P, 31 de julio de 1861, Escritura de venta de un censo sobre el cortijo de Arroyo de la Miel, con un resumen histórico de los sucesivos propietarios que tuvo y otras noticias relacionadas con el mismo, fol. 470-sigts. Documento inserto en AA.VV: Una Historia de... op. cit., págs. 286-289.

${ }^{54}$ A.H.P.M., Escribanía de don Manuel Romero de la Bandera, leg. 4688, 1861, Venta El Sr. D. Andrés Parladé contra D. Fernando Rumbado Morales, fols. 1146-1157v.
} 
Para la bendición y colocación de la primera piedra de la futura iglesia, el señor obispo designó a don Diego José Millán, quien acudió acompañado del licenciado don José Villaldes, párroco de la parroquia de los Santos Mártires.

Tras este acto, don Andrés se hizo cargo de que se iniciara la construcción de la iglesia, lo más pronto posible, en los terrenos adquiridos a don Fernando Rumbado que ocupaban 258 varas cuadradas y que lindaban al Este con tierras de don Juan Peralta, al Norte con la hacienda denominada las Pedrizas, propiedad del vendedor de los terrenos, al Oeste con el quebrado que daba agua a las fábricas de papel que alli existían y al Sur con el Camino Real.

Una vez concluida la construcción, que estaría bajo la abvocación de la Purísima Concepción, el señor obispo, en oficio del 24 de septiembre de 1863, comunicó al señor Andrés Parladé que iba a establecer una ayuda parroquial a la recién creada iglesia del Arroyo de la Miel. También solicitó, al citado señor Parladé, que la edificación que había costeado la entregara en propiedad a la iglesia. Don Andrés se negó indicando que cedía el uso del templo, pero que la propiedad sería tanto de él como de sus futuros herederos.

Posteriormente, la citada iglesia fue además dotada por el mismo matrimonio de las vestiduras, vasos sagrados y demás objetos necesarios y convenientes para el culto diario y el ornato de dicho templo. Esta ampliación fue comunicada al señor obispo el 30 de septiembre de 1864, quien en carta dirigida al señor Andrés Parladé, con fecha 5 de octubre de ese mismo año ${ }^{65}$, se dio por enterado de dicha ampliación del legado y, a su vez, comprendió las razones que llevaban a dicho matrimonio a no querer ceder la propiedad de lo donado. Los motivos no eran otros que evitar, en caso de repetirse procesos desamortizadores, la expropiación de dicha construcción y de los enseres que contenía.

Todos los objetos aportados por el matrimonio para la iglesia fueron valorados en 15.590 reales de vellón. Dichas piezas fueron las siguientes:

Cuatro amitos, su valor 120 reales.

Dos cordones para los mismos, 25 reales.

Tres albas a 200 reales una, 600 reales.

Dos cingulos de seda a 50 reales, 100 reales.

Dos cingulos de lana a 6 reales, 12 reales.

Cuatro casullas, su valor 1.140 reales.

Cuatro corporales, 100 reales.

Seis cornualtar, 30 reales.

${ }_{55}$ A.H.PM., Escribanía de don Manuel Romero de la Bandera, leg. 4699, 1865, Carta del
Obispo de Málaga a Don Andrés Parladé con fecha 5 de Octubre de 1864, fols. 261-264. 
Dos paños de altar a 100 reales, 200 reales.

Un hules para el mismo, 60 reales.

Un cáliz con su patena de plata sobredorada, su valor 800 reales.

Una cucharita para el mismo de plata, 12 reales.

Dos sobre patenas de plata, 20 reales.

Tres hijuelas para los corporales, 60 reales.

12 purificadores de hilo, 60 reales.

Un misal, 262 reales.

Un atril para el mismo, 57 reales.

Un incensario de metal, 105 reales.

Una naveta con su cucharita para incienso, 60 reales.

Dos vinajeras de cristal con su platillo de cristal, 16 reales.

Dos ciriales de bronce dorado, 228 reales.

Una cruz parroquial con crucifijo y varal de bronce, 171 reales.

Una caldereta de bronce con hisopo, 95 reales.

Tres pares de candeleros de metal dorado, 342 reales.

Una cruz de altar con crucificado de metal dorado, 190 reales.

Dos candeleros pequeños de bronce, 38 reales.

Una campanilla de metal, 12 reales.

Un crucifijo para la sacristia, de bronce, 30 reales.

Una caja con varios vasos de plata para la administración de los santos óleos, 800 reales.

Una espejo para la sacristía, 84 reales.

Una lámpara de metal plateada, 520 reales.

Un porta viático de plata gravado y dorado, 140 reales.

Un capillo de terciopelo con galón de oro para el copón, 80 reales.

Un vaso de cristal o sea purificador para los dedos, 8 reales.

Un bolso para el porta viático de terciopelo con galón de oro, 40 reales.

Un confesionario, 160 reales.

Cuatro bancos para la iglesia a 50 reales cada uno, 200 reales.

Una cajonera para la sacristía, 600 reales.

Copón de plata sobre dorado, 400 reales.

Tres cuadros con los evangelios y canon, 60 reales.

Una imagen de la Pura y Limpia Concepción, con su trono de talla, 2000 reales.

Otra imagen de San Pedro con su trono de talla, 1200 reales.

Otra de San Pablo también con su trono de talla, 1200 reales.

Un velo para el camarín de la Virgen, de damasco, 200 reales.

Otro velo para el tabernáculo con galón de oro, 160 reales.

Otro velo para el sagrario, 40 reales.

Una pila bautismal de mármol con su balaustre y tapadera, 740 reales.

Una concha de plata para bautizar, 160 reales.

Un tabernáculo y sagrario de talla, 1500 reales.

Dos paños de lienzo para el bautismo, 20 reales.

Cuatro ramas de flores contra hechas para el altar, 100 reales. 


Q. anteilos La burguesía malagueña y sus promociones ...

\section{Altar mayor de la antigua Parroquia de la Purísima Concepción, Arroyo de la Miel, Málaga}

Una alfombra para el mismo, 36 reales.

Una cortina para el óvalo, 42 reales.

Una escalera de manos, en 80 reales.

Entre las diversas imágenes escultóricas podemos observar la que iría dispuesta en el altar mayor por ser la patrona de esta iglesia de la Purísima Concepción y que se trata de la pieza de mayor valor de todo el inventario, 2000 reales de vellón. (Fig, 4)

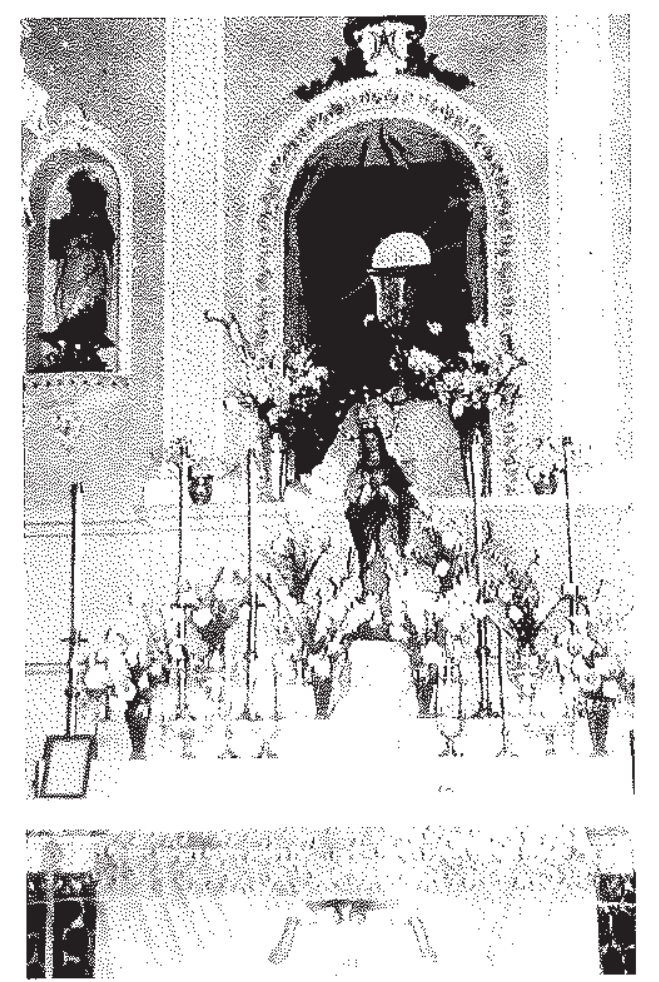

Según manifestaron al señor obispo, tanto el edificio como los objetos que contenía y que habían costeado el matrimonio formado por Andrés Parladé y María Heredia serían cedidos en préstamo al Arroyo de la Miel para su uso, pero la propiedad, tanto de la iglesia como de lo que contenía, sería del citado matrimonio y de sus futuros sucesores. De esa manera querían evitar un destino diferente al que ellos habían establecido. También se expuso que tanto los fundadores como sus sucesores tendrían derecho a sentarse en el presbiterio, siempre que acudiesen a dicho lugar a escuchar misa. En caso que el uso expuesto no se respetara, dicho templo con todos las piezas que hemos especificado en el inventario anterior, pasarian a poder de los descendientes del matrimonio y el edificio se convertiría en una capilla u oratorio de uso privado.

No obstante, los futuros gastos de reparación y conservación de dicha iglesia y la renovación de los bienes muebles para el culto y ornato de la misma que sufrieran deterioro por el uso, quedarían ya a cargo de los vecinos de la zona, del cura de Benalmádena, del obispado o de quien correspondiera. Igualmente, los promotores de esta obra se desentendían del sostenimiento del eclesiástico que fuera enviado por el señor obispo para oficiar en dicha iglesia. 

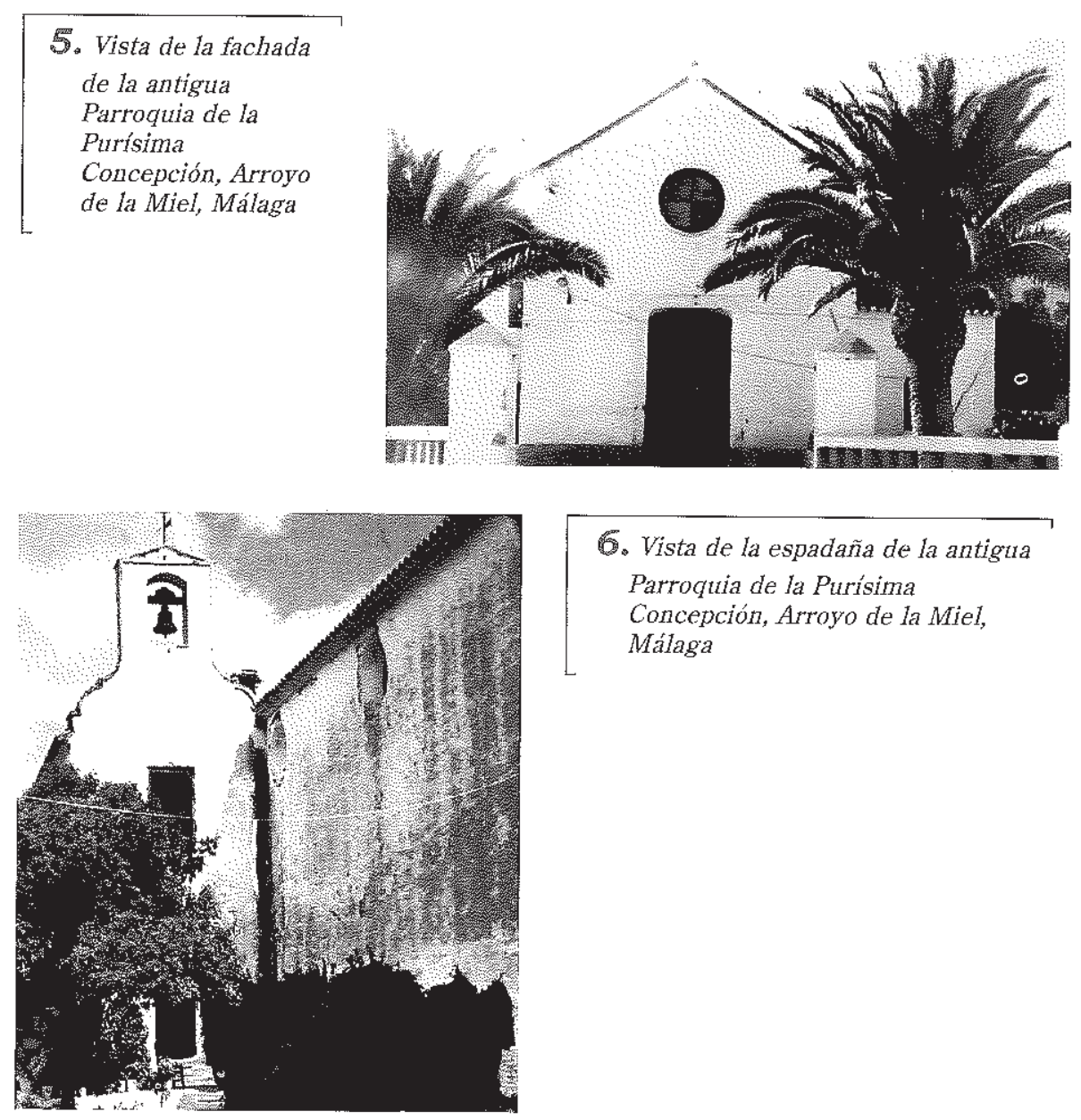

6. Vista de la espadaña de la antigua Parroquia de la Purísima Concepción, Arroyo de la Miel, Málaga

La aceptación de todas las condiciones y la cesión de la citada iglesia con todos los bienes que contenía fue realizada ante la presencia de don Gabriel Nicolich Pacheco, quien ante la ausencia del matrimonio promotor de la obra, residentes por esas fechas en Sevilla, fue nombrado el 23 de diciembre de 1864 representante de los mismos ${ }^{56}$, mientras el señor obispo, a su vez, envió al señor doctor don Juan García Guerra, presbítero canónigo penitenciario de la catedral malagueña y secretario de la autoridad episcopal de la Diócesis ${ }^{57}$.

Hacia 1910 un inventario de los bienes que poseía esta iglesia de la Purísima Concepción del Arroyo de la Miel nos permite comprobar que parte de los objetos donados por el matrimonio Parladé-Heredia aun permanecían en la misma. Concretamente se mantenían las tres imágenes escultóricas y se había aumentado el patrimonio mueble de la capilla con algunos cuadros religiosos: 


\section{Foto antigua. AI \\ fondo la antigua Parroquia de la \\ Purísima \\ Concepción, Arroyo \\ de la Miel, Málaga}
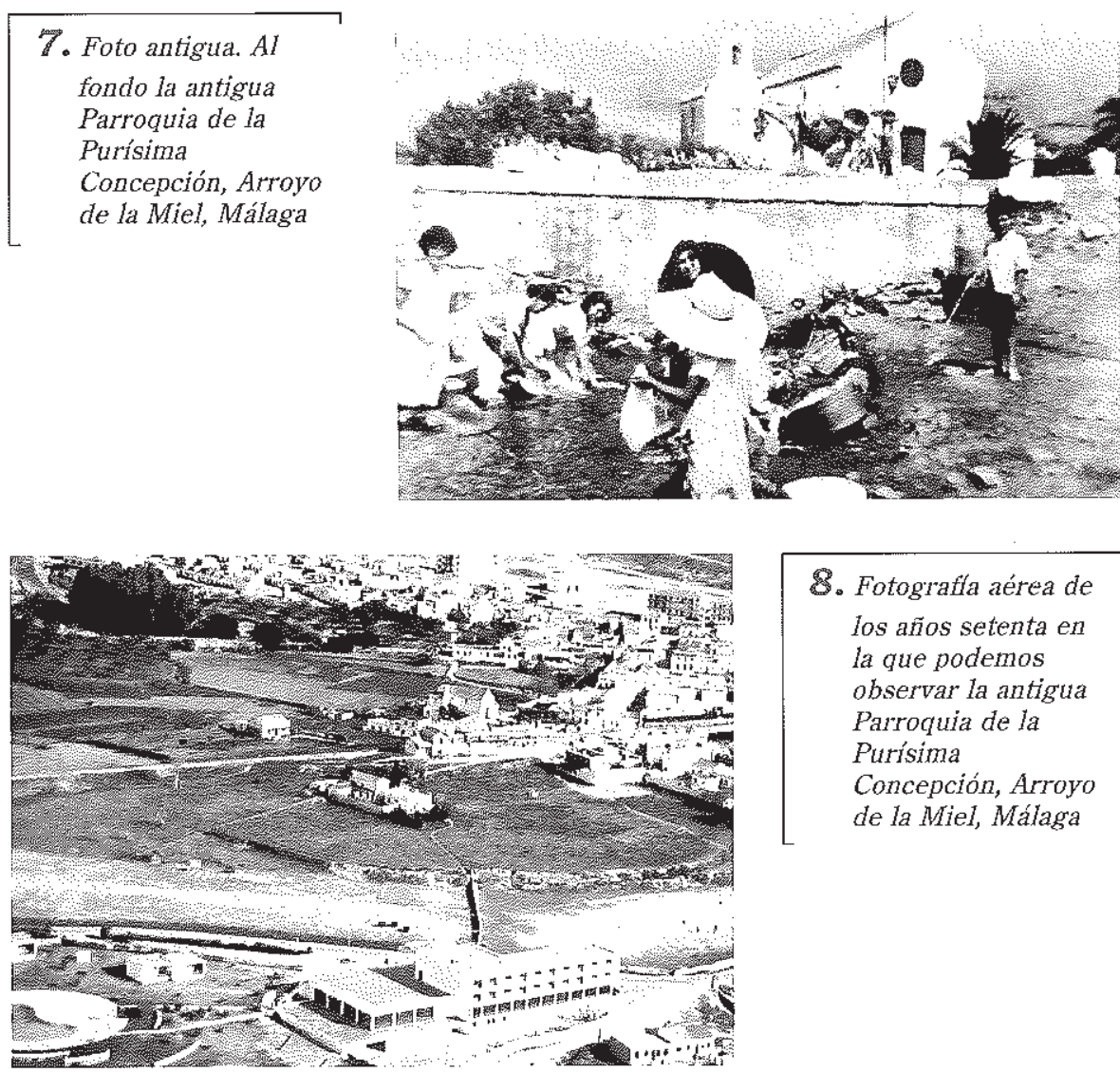

8. Fotografla aérea de los años setenta en la que podemos observar la antigua Parroquia de la Purísima

Concepción, Arroyo de la Miel, Málaga

Nuestra Señora de los Dolores.

Sagrado Corazón de Jesús.

Sagrado Corazón de María.

Colección de Via Crucis.

El Bautismo del Señoris.

${ }^{56}$ Dicha cesión de poderes fue realizada el 23 de diciembre de 1864 ante don Pabio María Olave, notario de Sevilla y una copia del documento aparece recogida en A.H.P.M., Escribanía de don Manuel Romero de la Bandera, leg. 4699, 1865, fols. 257-258v.

${ }^{57}$ A.H.P.M., Escribanía de don Manuel Romero de la Bandera, leg. 4699, 1865, Donación de uso de una Iglesia, ornamentos y vasos sagrados por los señores don Andrés Parladé y doña María Heredia Livermore, fol. 265-266v.

${ }^{58}$ (A)rchivo del (O)bispado de (M)álaga, Leg. 935, 1910, Inventario de enseres de la parroquia de Santo Domingo de Guzmán de la villa de Benalmádena y de la iglesia de la Purísima Concepción, de Arroyo de la Miel. Documento recogido en AA.VV: Una Historia de... op. cit., págs. 294-296. 


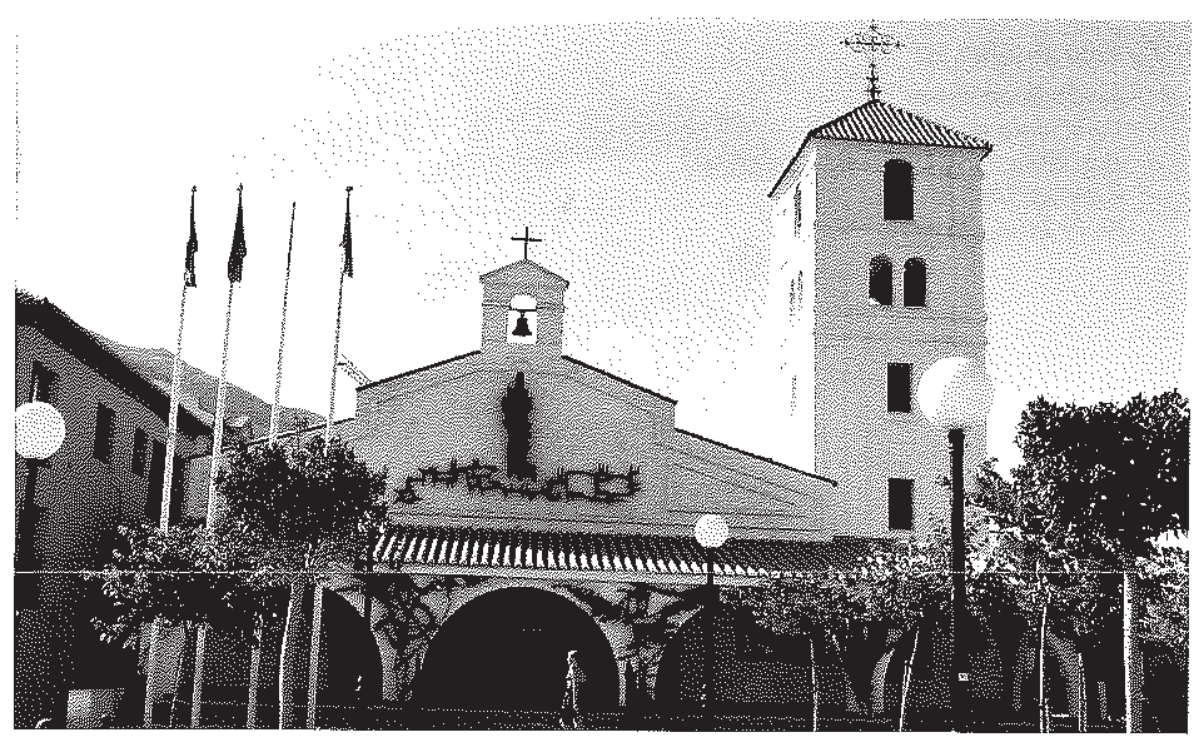

9. Fachada de la actual Parroquia de la Purísima Concepción, Arroyo de la Miel, Málaga

No apareciendo ya los tres cuadros legados por el matrimonio Parladé y siendo difícil conocer si otros objetos ornamentales eran los mismos o habian sido sustituidos por otros nuevos. También en este mismo documento se nos hace mención a una restauración sufrida en diciembre de 1912 por parte de la imagen de la Inmaculada Concepción.

Fotografías de comienzos del siglo $X X$ nos presentan una sencilla capilla encalada y con cubierta a dos aguas ( $F$ iG. 5) que presenta un campanario adosado (FiG. 6-7) y que puede tratarse de la edificación sufragada por el matrimonio Heredia. Se trata de una construcción acorde al resto de las construcciones de la villa ${ }^{59}$ (FIG. 8). En la actualidad existe otra construcción más reciente y de mayores dimmensiones de estilo neopopular. (FIG. 9)

\footnotetext{
${ }^{59}$ Agradezco la gran ayuda e informaciones prestadas por doña María del Carmen Martín de la Biblioteca Pública del Arroyo de la Miel y el haberme permitido adquirir imágenes de la capilla antigua de dicha localidad. Igualmente, agradezco la cordialidad con que fui tratada en la actual Parroquia del Arroyo de la Miel.
} 